Yoon-Ho Jang

Meong-Jin Eom

Kwang-Jun Paik*

Sang-Hyun Kim

Gisu Song

http://dx.doi.org/10.21278/brod71105

ISSN 0007-215X

eISSN 1845-5859

\title{
A NUMERICAL STUDY ON THE OPEN WATER PERFORMANCE OF A PROPELLER WITH SINUSOIDAL PITCH MOTION
}

\author{
UDC 629.5.016: 629.5.035:519.6
}

Original scientific paper

\begin{abstract}
Summary
When a ship operates in waves, the ship moves with 6 degrees-of-freedom, and a propeller at the stern of the ship cannot avoid moving due to the ship motion. Therefore, it is important to analyse the propulsion performance while considering the ship motion in waves for efficient ship operation. The pitch motion of the ship has a dominant effect on the variation of the propeller performance and results in sinusoidal pitch motion of the propeller. In this study, a numerical analysis was done using a KP458 model propeller with a diameter of $10 \mathrm{~cm}$, which was designed for the KLVCC2 body plan. The propeller performance was calculated using computational fluid dynamics (CFD) at several constant tilt angles. Numerical simulations were then conducted with sinusoidal pitch motion in several conditions of varying pitch angle. The variations of the thrust and torque of the propeller in sinusoidal pitch motion were compared with the results obtained in constant tilt angles.
\end{abstract}

Key words: CFD; Propeller performance; Sinusoidal pitch motion; Tilt angle

\section{Introduction}

Traditionally, ships have been optimized for calm water operation. Many studies have been carried out on the resistance and propulsion performance of ship in calm water. However, the International Maritime Organization (IMO) introduced the Energy Efficiency Design Index (EEDI) in 2013 to regulate the emissions of greenhouse gases from ships. Therefore, studies on the added resistance due to ship motion in waves have been of interest. Many studies on the optimization of the hull form to improve the operational efficiency were carried out, and new design concepts for the bow of ship were proposed as the results. However, just a few studies have been conducted on the propulsion performance of ships with periodic motion in waves.

A ship operating in waves has very complex movements. Particularly, the propeller attached on the ship astern can experience surface piercing and air ventilation due to pitch and heave motions. As a result, the propulsion efficiency could be reduced due to the loss of thrust and torque. 
Air ventilation is a phenomenon where a propeller interacts with the free surface and pulls down air when it operates beneath the free surface. This phenomenon depends on many conditions, such as the propeller loading, advance speed, and the distance from the propeller to the free surface [1,2]. Kempf [3] was a pioneer in the study of ventilation according to the revolution and immersion depth. Shiba [4] researched the phenomenon with different propeller shapes. Koushan [5] presented experimental results on the effects of ventilation of a propeller in an open-water test at constant revolutions and different immersion depths under the bollard condition. Kozlowska et al. [6] presented mechanisms of the air flow phenomena of a propeller, which were classified according to the immersion depth and the occurrence of a vortex funnel. They compared the results with a previously reported thrust reduction estimation equation and experimental results. Kozolowska et al. [7] suggested a complementary estimation formula that depends on the advance coefficient and immersion depth.

Studies haves also been carried out on the performance estimation of a propeller that experiences periodic waves based on the relationship with the free surface and air ventilation phenomena [8 10]. Another study looked at the open-water characteristics and the load on the shaft axis for a propeller with sinusoidal heave motion [11 12].

However, there have been just a few studies on a propeller or thruster with sinusoidal pitch motion, even though they also have pitching motion in wave condition. Studies have been conducted on azimuth thrusters, and the forces acting on the shaft of the propeller with a yaw angle with respect to the propeller advance direction. Amini and Steen [13], Li et al. [14], and Shamsi and Ghassemi [15] studied the changes in the thrust and torque in an oblique flow of a propeller moving left and right. When the thrust and torque change varying in a small range of angles $\left(-10^{\circ}\right.$ to $\left.10^{\circ}\right)$, they did not show a significant difference within the error range of the measured values. However, the thrust and torque increased at a larger angle as the advance coefficient increased and as the angle gradually increased.

This paper examines the changes in performance of a propeller due to pitch motion. To confirm the reliability of the numerical analysis method, a validation was done with propeller open water (POW) test results from the National Maritime Research Institute (NMRI). A numerical analysis was then performed using POW test characteristics at three immersion depths and five tilt angles to study the effects on the propeller performance. A propeller with sinusoidal pitch motion was then studied using numerical analysis. Finally, the performance of the propeller and the flow structure around it were investigated.

\section{Numerical analysis conditions}

\subsection{Propeller geometry}

The KP458 propeller model was designed by the Korea Research Institute of Ships and Ocean Engineering (KRISO) for a KVLCC tanker ship. The full-scale propeller has a diameter of $9.86 \mathrm{~m}$ and 4 blades. Table 1 shows the specifications. The propeller geometry used in the numerical analysis is shown in Figure 1.

\subsection{Calculation conditions}

The commercial CFD program STAR-CCM+ 12.06 was used for the numerical analysis. This numerical simulation study was performed and verified through comparison with model test results. The first calculation was carried out by varying the immersion depth and advance coefficient with respect to the tilt angle $\left(-10^{\circ}, 0^{\circ}, 10^{\circ}\right)$ and sinusoidal pitch motion $\left(-10 \sim 10^{\circ}\right)$. The numerical analysis conditions for the tilted propeller are shown in Table 2 . The pitching motion was applied with advance coefficients of $0.1,0.3,0.5$, and 0.7 , and $\mathrm{h} / \mathrm{D}=2.0$. 


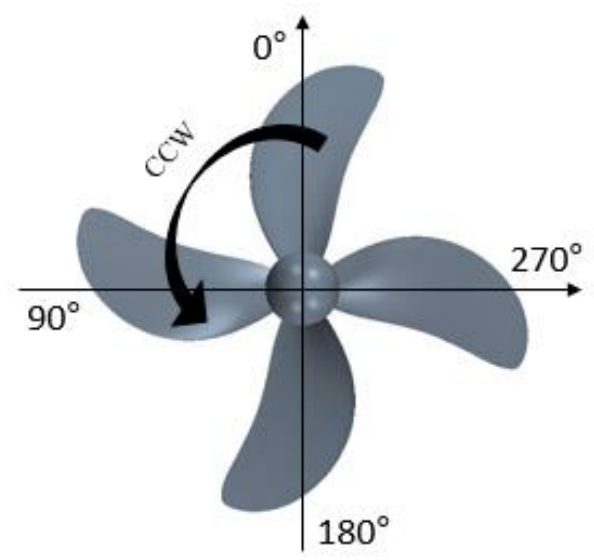

Fig. 1 KP458 propeller model

Table 1 specifications of the propeller model (KP458)

\begin{tabular}{|l|l|}
\hline Diameter $(\mathrm{mm})$ & 100.0 \\
\hline Scale ratio & 98.6 \\
\hline No. of blades & 4 \\
\hline P/D (mean) & 0.690 \\
\hline Ae/Ao & 0.431 \\
\hline Hub ratio & 0.155 \\
\hline Section & NACA66 \\
\hline
\end{tabular}

Table 2 calculation conditions for tilted propeller

\begin{tabular}{|c|c|c|c|c|c|c|c|c|c|c|c|c|c|c|c|}
\hline $\mathrm{h} / \mathrm{D}$ & \multicolumn{9}{|c|}{2.0} & \multicolumn{5}{|c|}{1.0} & \multicolumn{5}{c|}{0.5} \\
\hline Tilt angle $\left(^{\circ}\right)$ & -10 & -5 & 0 & 5 & 10 & -10 & -5 & 0 & 5 & 10 & -10 & -5 & 0 & 5 & 10 \\
\hline $\mathrm{J}_{\mathrm{A}}=0.1$ & $\circ$ & & $\circ$ & & $\circ$ & $\circ$ & & $\circ$ & & $\circ$ & $\circ$ & & $\circ$ & & $\circ$ \\
\hline $\mathrm{J}_{\mathrm{A}}=0.3$ & $\circ$ & & $\circ$ & & $\circ$ & $\circ$ & & $\circ$ & & $\circ$ & $\circ$ & & $\circ$ & & $\circ$ \\
\hline $\mathrm{J}_{\mathrm{A}}=0.5$ & $\circ$ & $\circ$ & $\circ$ & $\circ$ & $\circ$ & $\circ$ & & $\circ$ & & $\circ$ & $\circ$ & $\circ$ & $\circ$ & $\circ$ & $\circ$ \\
\hline $\mathrm{J}_{\mathrm{A}}=0.7$ & $\circ$ & & $\circ$ & & $\circ$ & $\circ$ & & $\circ$ & & $\circ$ & $\circ$ & & $\circ$ & & $\circ$ \\
\hline
\end{tabular}

Figure 2 shows the concept of the numerical analysis model. The thrust values were measured with the $\mathrm{x}$-axis pointing in the direction that the ship moves. All torque values were measured in the direction of the rotating shaft axis because it is related to the power from the ship's engine. The conditions of the sinusoidal pitch motion were determined by considering the sea conditions and the body motion of the KVLCC2. Park et al. [16] and Kim et al. [17] studied the added resistance and ship motion of the KVLCC2. The pitch response amplitude operator (RAO) is dimensionless and determined by the ratio of the pitch amplitude, wave amplitude, and wave number, as shown in below

$$
\frac{\theta}{A k}=\frac{\theta \times \lambda / L}{(A / L) \times 360}
$$

The pitch angle $(\theta)$ depends on the wavelength $(\lambda)$ and wave amplitude $(A)$. Therefore, the calculation conditions of the pitching range for the sinusoidal pitching propeller were selected as $-10^{\circ}$ to $10^{\circ}$ based on the assumption that the pitching angle would be large enough if the wave conditions are severe. The period of the pitching motion was also determined by considering the wavelength and ship length. The period was set as 1 second to obtain a short wavelength in order to shorten the simulation times. Figure 3 shows the sinusoidal tilt angle of the pitching propeller used in the numerical analysis. 


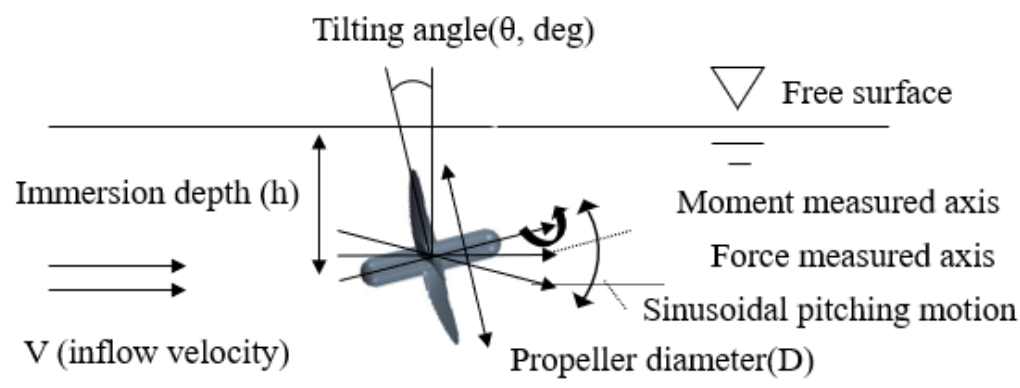

Fig. 2 The concept of the numerical analysis model

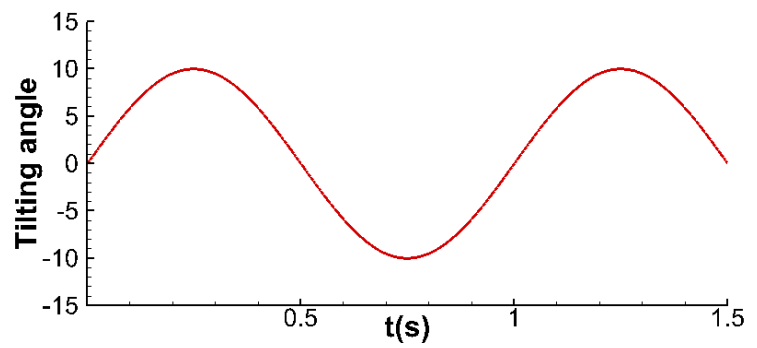

Fig. 3 Sinusoidal tilt angle of the pitching propeller used in the numerical analysis

\subsubsection{Governing equations}

The continuity equation and incompressible Reynolds averaged Navier-Stokes (RANS) equations were used to consider the three-dimensional unsteady and incompressible viscous flows:

$$
\begin{aligned}
& \frac{d}{d t} \int_{\Omega} \rho d \Omega+\int_{S} \rho u_{i} n_{i} d S=0 \\
& \frac{d}{d t} \int_{\Omega} \rho u_{i} d \Omega+\int_{S} \rho u_{i} u_{j} n_{j} d S=\int_{S}\left(\tau_{i j} n_{j}-p n_{i}\right) d S+\int_{\Omega} \rho b_{i} d \Omega
\end{aligned}
$$

$\rho$ and $p$ are the density and pressure, respectively, $u_{i}$ is the velocity tensor and $b_{i}$ is the tensor of body forces, and $\tau_{i j}$ is the effective stress of the viscosity and turbulence, which is defined as follows using the dynamic viscosity $\mu_{e}$ :

$$
\tau_{i j}=\mu_{e}\left[\left(\frac{\partial u_{i}}{\partial x_{j}}+\frac{\partial u_{j}}{\partial x_{i}}\right)-\frac{2}{3} \delta_{i j} \frac{\partial u_{k}}{\partial x_{k}}\right]
$$

The governing equations were solved using a finite volume method with a second orderaccuracy discretization technique provided by STAR-CCM + . The SST k- $\omega$ turbulence model was used for the turbulence model, which computes the k- $\omega$ turbulence flow inside the boundary layer and the k- $\varepsilon$ turbulence model outside the boundary layer together. The pressurevelocity coupling was implemented using the SIMPLE (Semi-Implicit Method for PressureLinked Equations) algorithm.

For the convection term, the total time derivative has to be modified to account for grid velocities. The total time derivative is expressed as the ALE (Arbitrary Lagrangian-Eulerian) formulation for a generic variable $\varphi$ :

$$
\frac{D \varphi}{D t}=\frac{\partial \varphi}{\partial t}+\nabla \cdot[(u-\dot{x}) \varphi]
$$

where $\dot{x}$ is the grid velocity vector.

\subsubsection{Grid system}

Figure 4 shows computational domain and boundary conditions. Domain size is set as $4 \mathrm{~m}$ $\times 3 \mathrm{~m} \times 6 \mathrm{~m}$ (width $\times$ height $\times$ length $)$. 


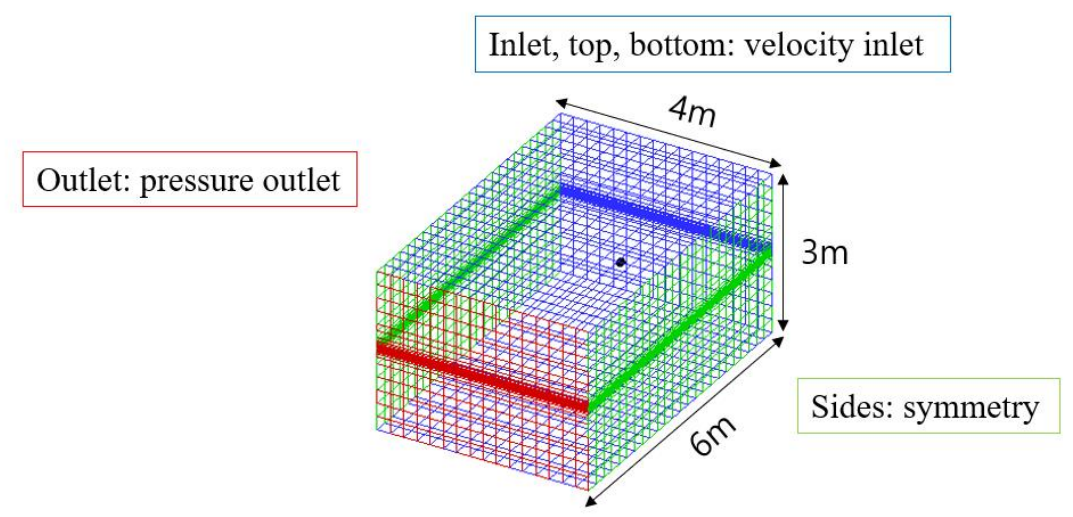

Fig.4 Computational domain and boundary conditions

An overset mesh technique was used to discretize the computational domain with several different grids that overlap each other. A surface remesher, prism layer, and trimmer mesh were applied to this grid system, which is shown in Figure 5. Figure 5 (a) shows a grid system in which the propeller is not tilted $\left(\theta=0^{\circ}\right)$, and Figure 5 (b) shows a grid system for a propeller with a tilt angle $\left(\theta=10^{\circ}\right)$. The grid system was made to be denser around the free surface to observe the complex flow structure near this area. The mesh elements of $1.4 \mathrm{M}$ were used for the rotating propeller block, and the mesh elements of $1.7 \mathrm{M}$ were used for the background, including the free surface.

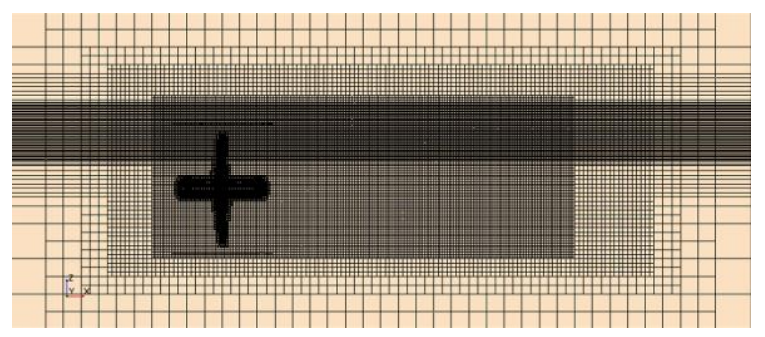

(b) Tilt angle $(\theta)=0^{\circ}$

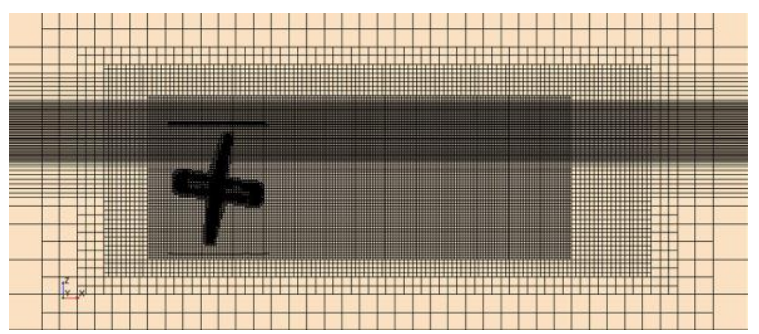

(c) Tilt angle $(\theta)=10^{\circ}$

Fig. 5 Grid system for a tilted propeller under a free surface/

\section{Results and discussion}

\subsection{Validation}

The characteristics of the POW performance were compared with the KP458 results presented by the NMRI to validate the numerical analysis. The Reynolds number was calculated at $0.7 \mathrm{R}$ based on the blade chord length and relative flow rate, $V_{R}=\sqrt{V_{A}^{2}+(0.7 \pi n D)^{2}}$, as recommended by the International Towing Tank Conference (ITTC). The propeller rotations from the NMRI results and the present simulation were $43.62 \mathrm{rps}$ and $32.55 \mathrm{rps}$, respectively. The Reynolds numbers were $2.07 \times 10^{5}$ and $1.93 \times 10^{5}$ at $J_{A}=0.5$. A numerical analysis of the KP458 operating without the free surface was carried out with advance coefficients of 0.1 , 
$0.3,0.5$, and 0.7. A verification was then performed through comparison with the POW test results from the NMRI.

The torque and thrust in the simulation show good agreement with the NMRI's experimental data at all advance coefficients with an error rate of $1-2 \%$ except for $J_{A}=0.7$, which has small thrust and torque. The coefficients of the thrust and torque provided by the NMRI and the present numerical analysis are shown in Table 3. Figure 6 shows a graph of the POW performance according to the advance coefficient.

Table 3 Comparison of POW characteristics between the NMRI and present CFD results

\begin{tabular}{|c|c|c|c|c|c|c|}
\hline \multirow{2}{*}{$J_{A}$} & \multicolumn{2}{|c|}{ NMRI (EFD) } & \multicolumn{2}{c|}{ Present (CFD) } & \multicolumn{2}{c|}{ Error rate (\%) } \\
\cline { 2 - 7 } & $K_{T}$ & $10 K_{Q}$ & $K_{T}$ & $10 K_{Q}$ & $K_{T}$ & $10 K_{Q}$ \\
\hline 0.1 & 0.265 & 0.288 & 0.263 & 0.282 & 0.96 & 1.80 \\
\hline 0.3 & 0.199 & 0.234 & 0.197 & 0.230 & 1.10 & 1.50 \\
\hline 0.5 & 0.117 & 0.161 & 0.118 & 0.163 & -1.01 & -0.99 \\
\hline 0.7 & 0.034 & 0.078 & 0.031 & 0.076 & 10.20 & 2.53 \\
\hline
\end{tabular}

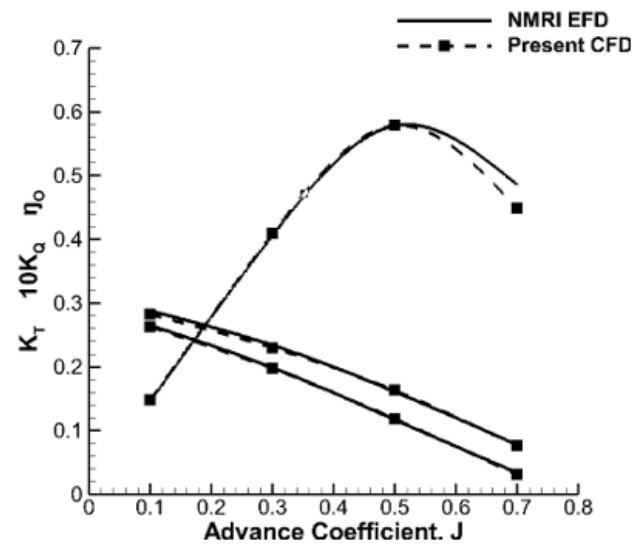

Fig. 6 Comparison of POW characteristics

\subsection{POW performance at different tilt angles}

The performance of the propeller was estimated while considering only the tilt angles without the influence of the free surface. To achieve this, a POW test was carried out with $\mathrm{h} / \mathrm{D}=2.0$ and tilt angles of $-10^{\circ},-5^{\circ}, 0^{\circ}, 5^{\circ}$, and $10^{\circ}$. The axis direction in which the thrust was measured was aligned with the $\mathrm{x}$ axis. The torque axis of the numerical simulations was changed according to the tilt angle because the torque was measured about the shaft axis.

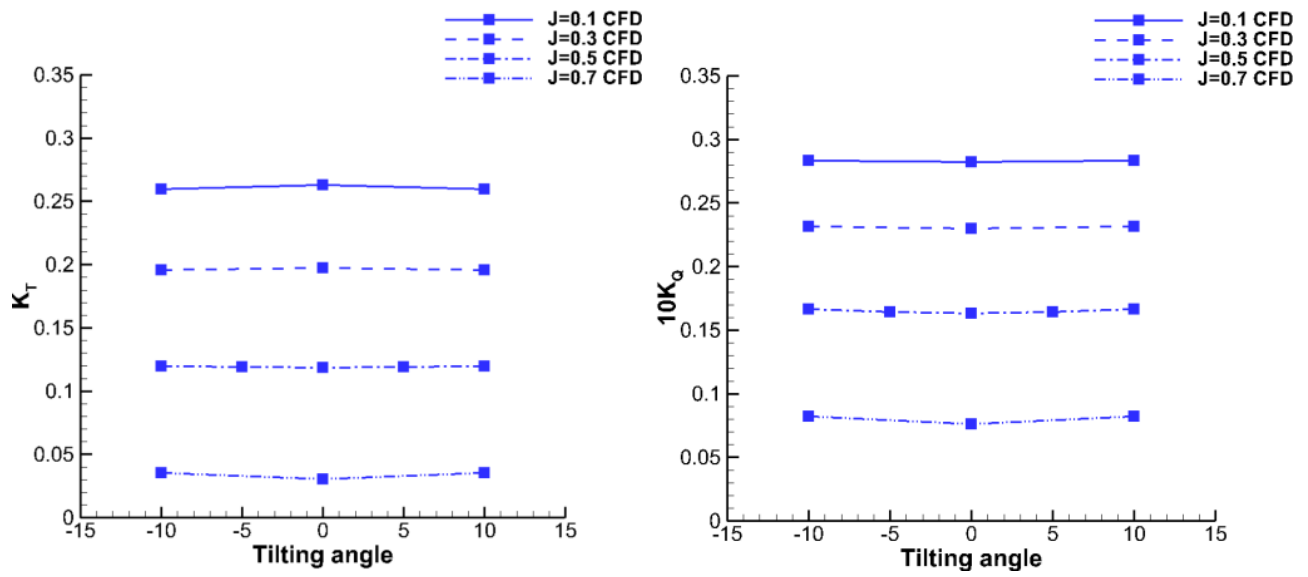

Fig.7 Comparison of thrust (left) and torque (right) coefficients according to the tilt angle (h/D=2.0) 
Figure 7 presents the changes in the thrust and torque coefficients according to the tilt angle at each advance coefficient. The thrust coefficient tended to decrease as the angles increased at advance coefficients of 0.1 and 0.3 . At advance coefficients of 0.5 and 0.7 , however, the thrust coefficient tended to increase as the angles increased. The torque coefficient gradually increased as tilt angle and advance coefficients increased.

These results seem to be due to the difference of the measuring axis of the thrust and torque. The thrust and torque magnitudes depend on the advance coefficient. When the propeller has a tilt angle, the advance coefficient decreases and causes an increase in the thrust and torque. However, in the case of the measured thrust, the thrust is reduced as the angle increases at a lower advance coefficient because it is aligned in the $\mathrm{x}$-axis direction. When the propeller has a tilt angle, the thrust and torque coefficients change by $1 \%$ according to the advance coefficients. It is assumed that the tilt angle is not a dominant factor in the propeller performance.

\subsection{Propeller performance at different immersion depths}

The propeller performance was compared according to the immersion depth from the free surface, and numerical analyses were carried out at three tilt angles $\left(-10^{\circ}, 0^{\circ}, 10^{\circ}\right)$, four advance coefficients $\left(J_{A}=0.1,0.3,0.5,0.7\right)$, and three immersion depths of water $(\mathrm{h} / \mathrm{D}=2.0,1.0,0.5)$. The performance of the propeller is reduced by the interaction with the free surface as the propeller approaches the free surface. The dynamic pressure and volume fraction results were compared using three different immersion depths and two different advance coefficients, as shown in Figure 8 . When the propeller is closer to the free surface, the interaction with the free surface is stronger. The interaction with the free surface also increases at lower advance coefficient.

\section{Suction side}

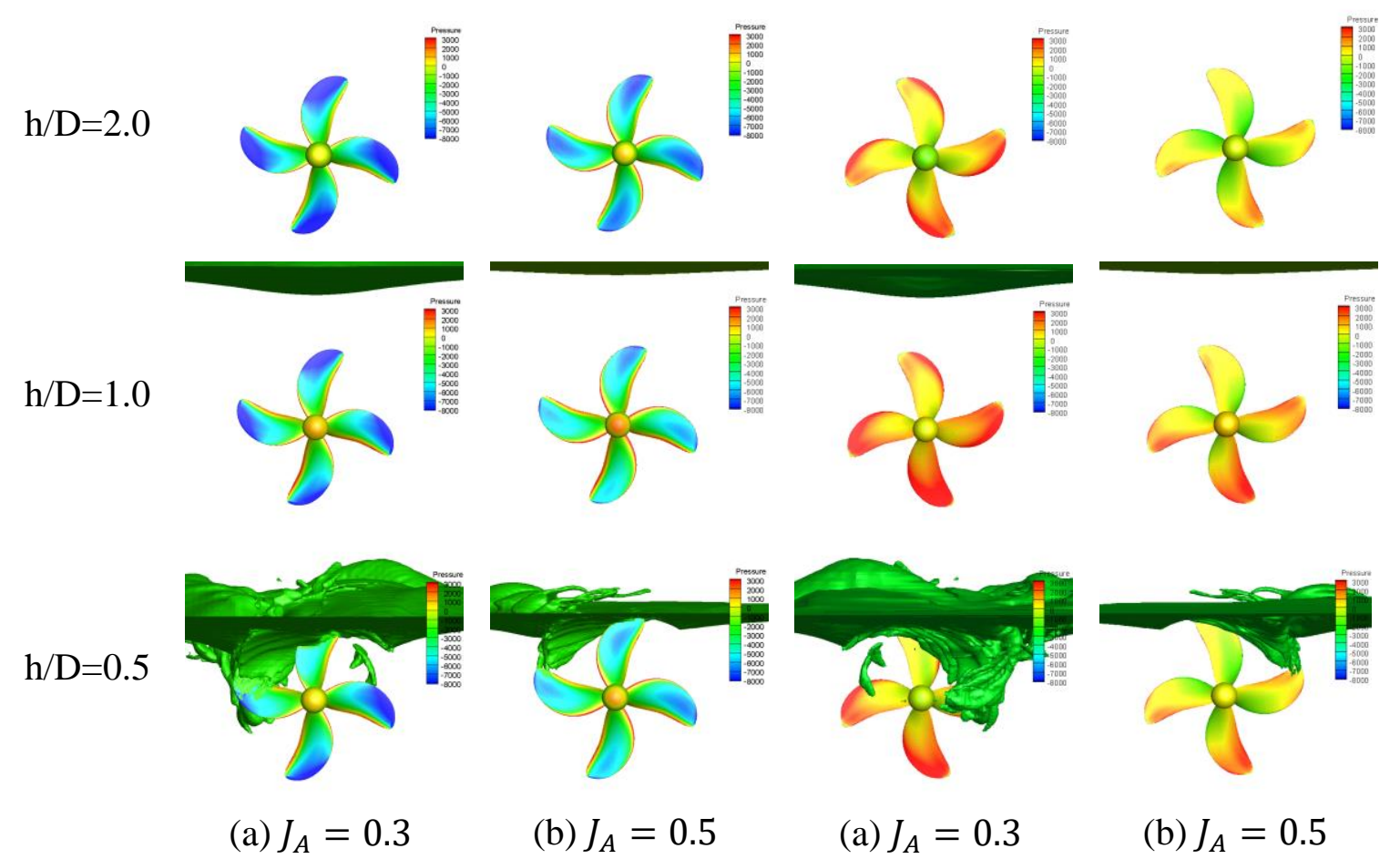

Fig.8 Comparison of the free surface and dynamic pressure according to advance coefficient and immersion depth (the free surface is plotted with 0.5 volume fraction of air)

The dynamic pressure on the suction side decreases when the blade starts to interact with free surface at $h / D=1.0$ and $h / D=0.5$. Each of the blades has different dynamic pressure 
according to its location. The magnitude of the pressure of the blade at the top was lower than that of the blade at the bottom position due to the interaction with free surface, and the pressure difference was greater at lower advance coefficients. The change in pressure distribution due to the interaction with free surface persists after the propeller blade passes top position.

Figure 9 presents the angular variation of the thrust and torque according to the immersion depth and advance coefficients. The thrust and torque were nondimensionalized with the average thrust and torque on one blade at a tilt angle of $0^{\circ}$ and $\mathrm{h} / \mathrm{D}=2.0$. As the immersion depth decreases, the fluctuation of the thrust and torque depending on the angle increases. At $h / D=0.5$, the thrust suddenly decreases at around $300^{\circ}$ and tends to recover $70^{\circ}$. A lower advance coefficient also results in greater loss of thrust. In the case of $\mathrm{h} / \mathrm{D}=1.0$, which is shallower than $\mathrm{h} / \mathrm{D}=2.0$, losses of approximately $1 \%$ occurred in the thrust and torque. The thrust and torque change according to the position of the propeller. It is possible to explain this by the pressure change on the suction side, as shown in Figure 8.
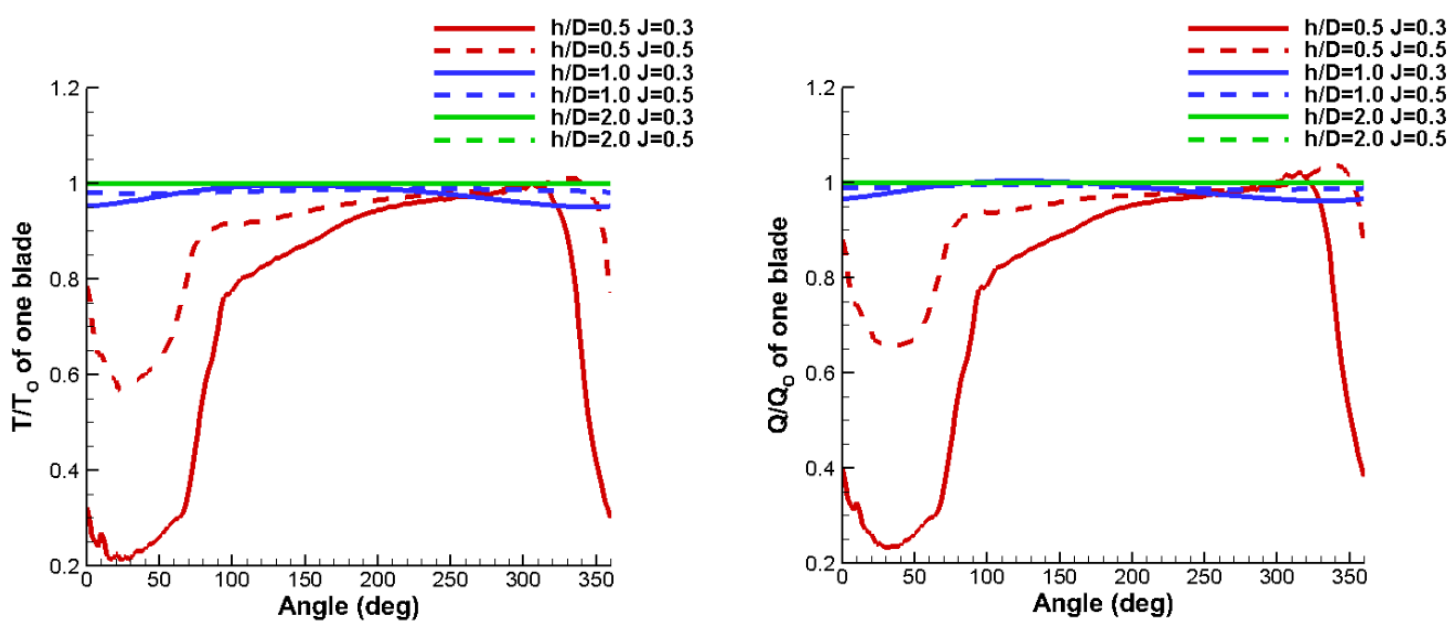

Fig.9 Comparison of the angular variations of nondimensionalized thrust (left) and torque (right) of one blade according to the immersion depths and advance coefficients $\left(\theta=0^{\circ}\right)$.

Figure 10 shows the POW characteristics with different immersion depths and tilt angles. The thrust coefficient and torque coefficient at $h / D=1.0$ are similar to those at $h / D=2.0$. At $h / D=0.5$, the thrust and torque more decreased at low advance coefficient than that of $h / D=2.0$. This is due to surface piercing and air ventilation, which can be observed in Figure 8.

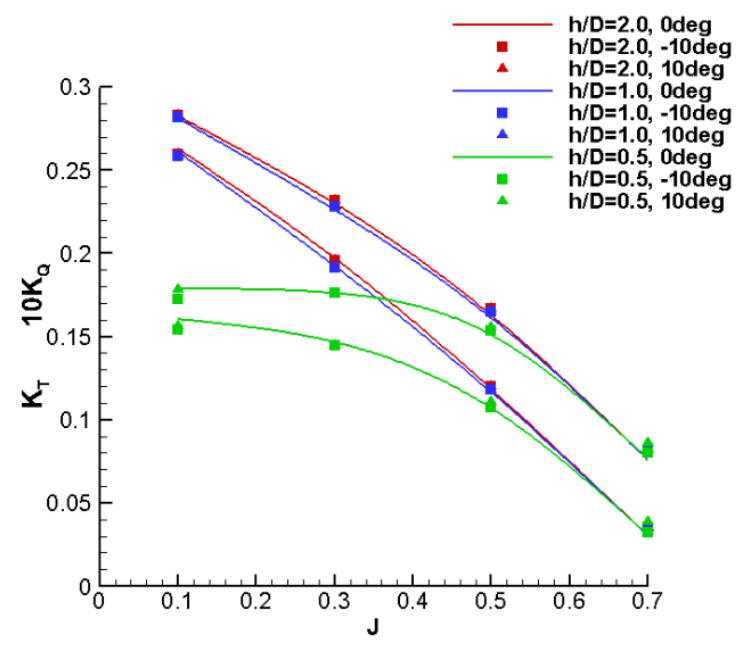

Fig.10 Comparison of POW characteristics according to the immersion depths and tilt angles of the propeller 
The changes in the thrust and torque coefficients according to immersion depth and tilt angle show similar tendencies to the simulation data at $\mathrm{h} / \mathrm{D}=2.0$. However, the magnitude of the thrust and torque at $h / D=0.5$ are more reduced as the angle increases than in the previous data measured at $h / D=2.0$. Figure 11 shows that the $Q$-criterion at $10^{\circ}$ and $-10^{\circ}$ at $h / D=0.5$ is larger than that at $0^{\circ}$. This occurred because when the propeller has a tilt angle, the lower water level causes more severe interaction with the free surface, resulting in high vorticities of the tilted propeller. However, as mentioned, the increase in the coefficient according to the tilt angle is too small to show significant effects.

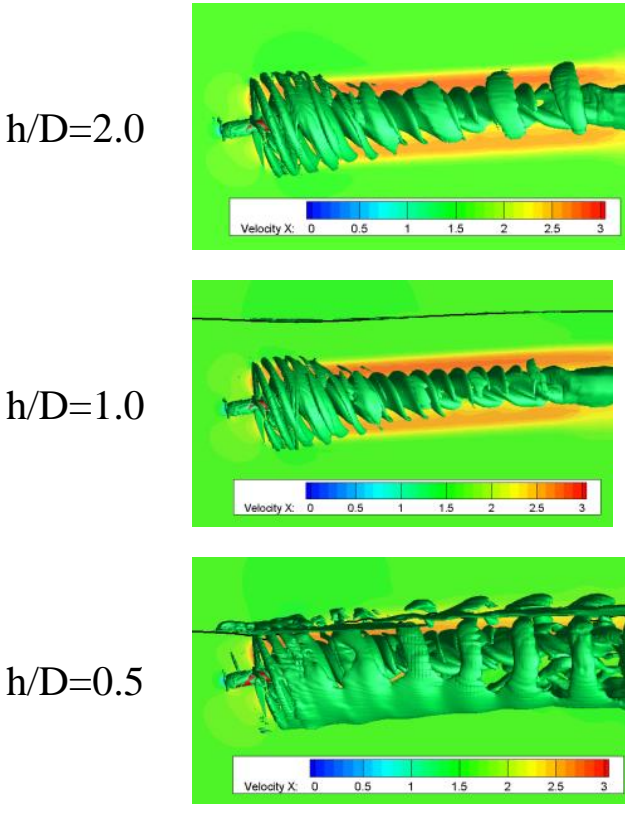

(a) $-10 \mathrm{deg}$
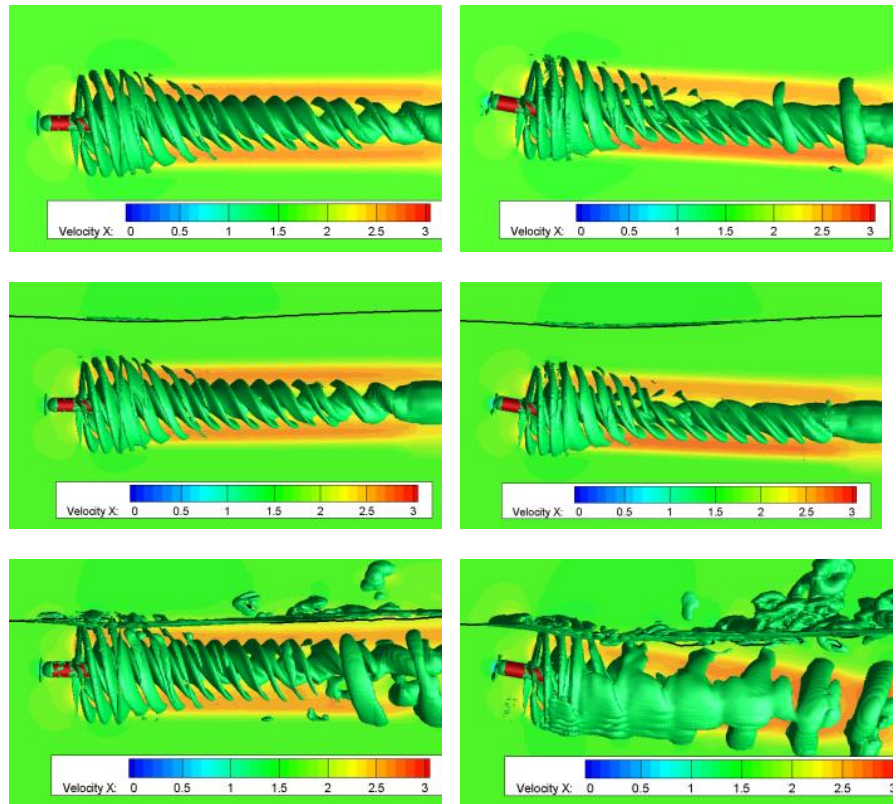

(b) Odeg

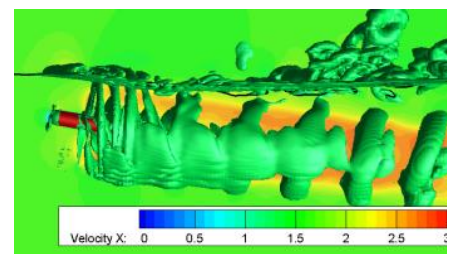

(c) $10 \mathrm{deg}$

Fig.11 Comparison of Q-criterion (50), $\mathrm{x}$-axis velocity and free surface according to the immersion depths and tilt angles at $J_{A}=0.5$

In Figure 11, when there is no angle, the velocity profile of the propeller wake is the same at the top and bottom sides of the propeller. However, the upper wake becomes stronger and the lower wake becomes weaker at $-10^{\circ}$. This phenomenon is opposite at $10^{\circ}$. Figure 12 presents the angular variation of the thrust according to the tilt angle and advance coefficients at different immersion depths. The thrust is nondimensionalized with the average thrust on one blade at a tilt angle of $0^{\circ}$ and $\mathrm{h} / \mathrm{D}=2.0$. In the case of $\mathrm{h} / \mathrm{D}=2.0$ and $\mathrm{h} / \mathrm{D}=1.0$, thrust fluctuation had similar tendency with each other. However, the maximum thrust can be observed in different blade location according to the propeller tilt angle. When the blade located in near the $0^{\circ}$, thrust of $10^{\circ}$ tilted propeller was high, which causes the wake velocity to increase partially on the top side. When the blade located in near the $180^{\circ}$, thrust of $10^{\circ}$ tilted propeller was high, which causes the wake velocity to increase partially on the bottom side. It seems that a different angle of attack on the propeller affects the propeller performance according to the blade location.

\subsection{POW performance in sinusoidal pitch motion}

Figure 13 shows the change of the propeller operating conditions due to ship motion. Both the tilt angle and immersion depth change due to the pitch motion. To observe the effect of the only tilt motion on the POW performance, the tilting propeller was modeled for the numerical simulation. 


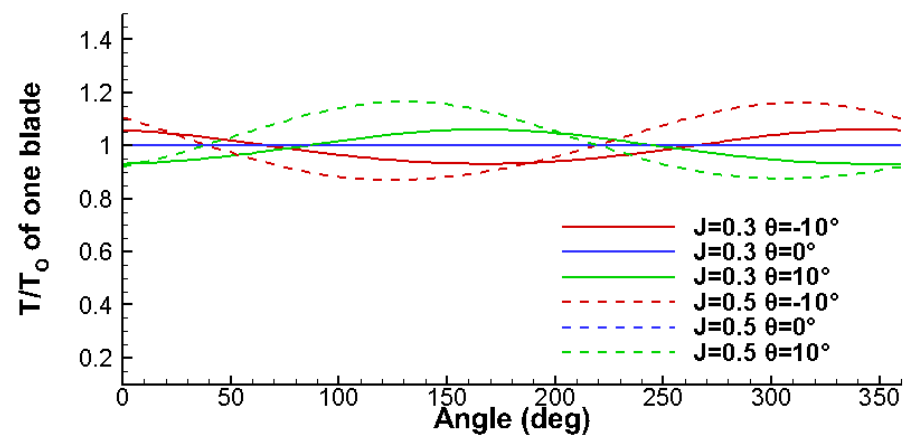

(a) $\mathrm{h} / \mathrm{D}=2.0$

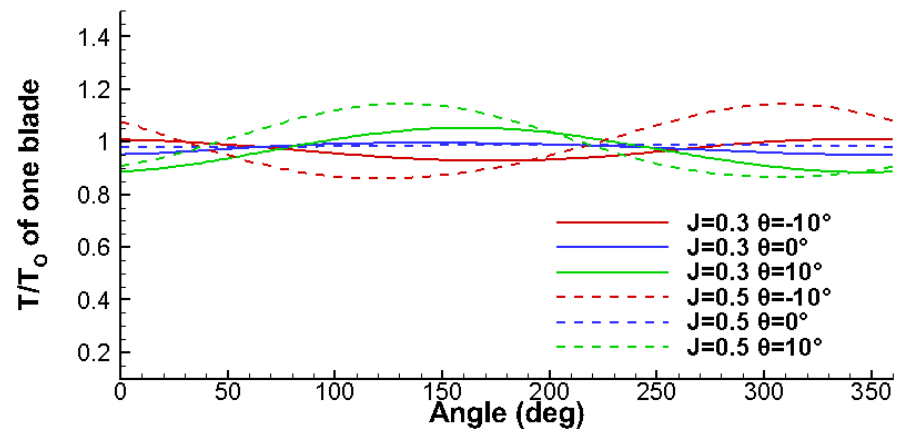

(b) $\mathrm{h} / \mathrm{D}=1.0$

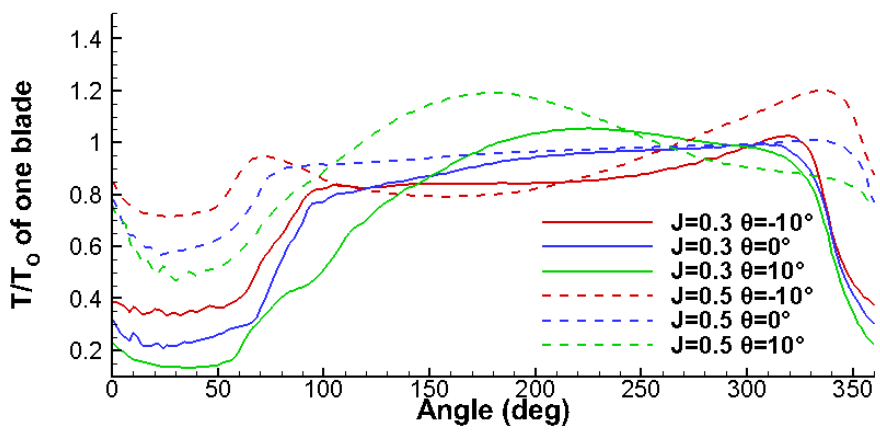

(c) $\mathrm{h} / \mathrm{D}=0.5$

Fig.12 Angular variations of the thrust of one blade according to the tilt angle and advance coefficient.
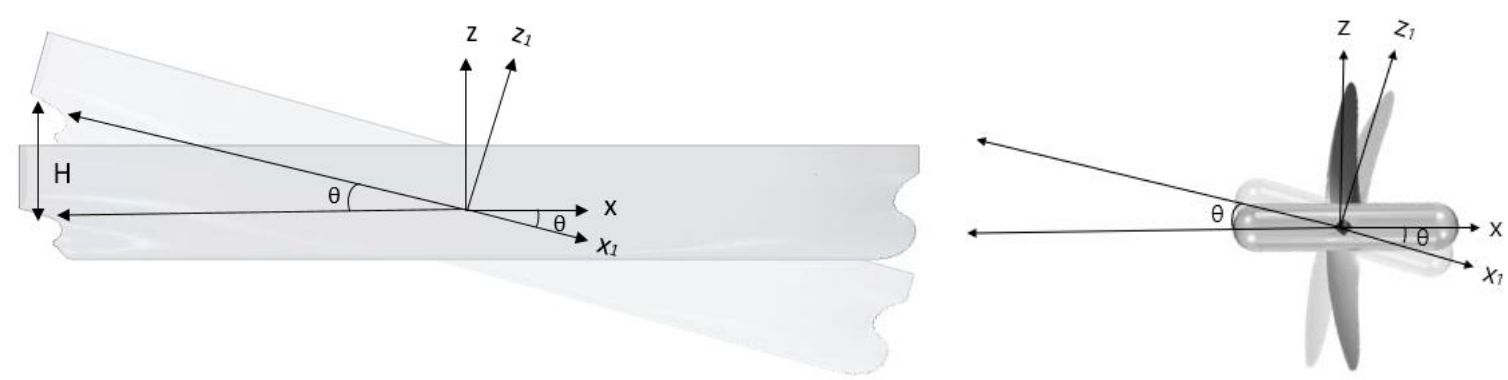

Fig. 13 Coordinate systems for a ship (left) and a propeller (right) operating with pitch motion in waves

A numerical analysis of the sinusoidal pitch motion was carried out while changing the advance coefficient at different immersion depth. Figure 14 shows the comparison of the thrust and torque coefficients obtained with and without pitch motion in different immersion depth. 
A Numerical Study on the Open Water Performance of a Propeller with Sinusoidal Pitch Motion
Yoon-Ho Jang, Meong-Jin Eom Kwang-Jun Paik, Sang-Hyun Kim, Gisu Song

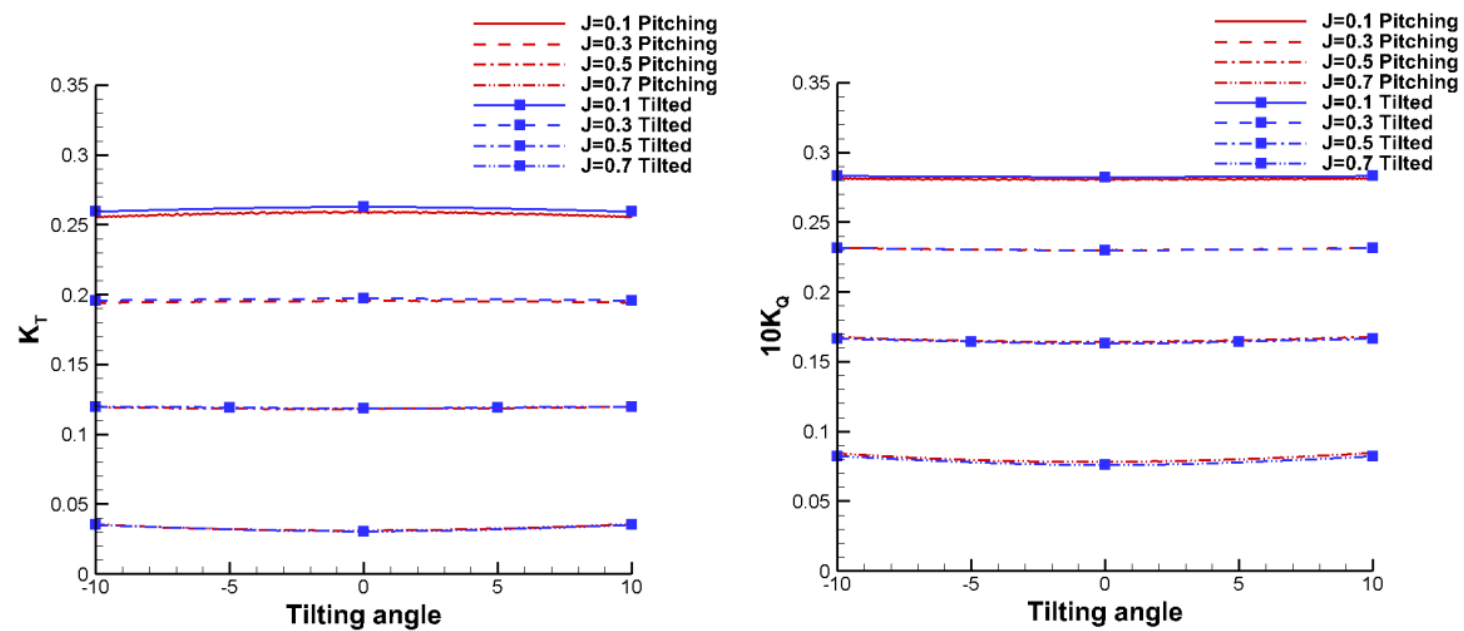

(a) $\mathrm{h} / \mathrm{D}=2.0$

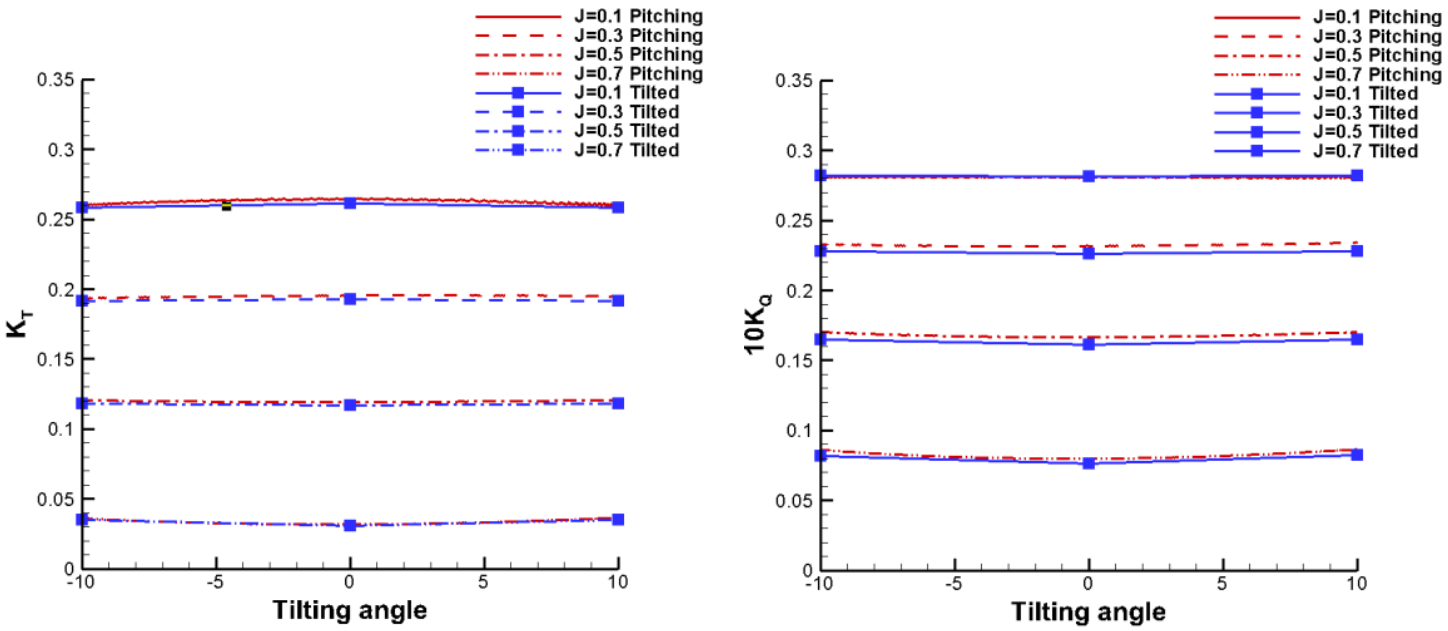

(b) $\mathrm{h} / \mathrm{D}=1.0$

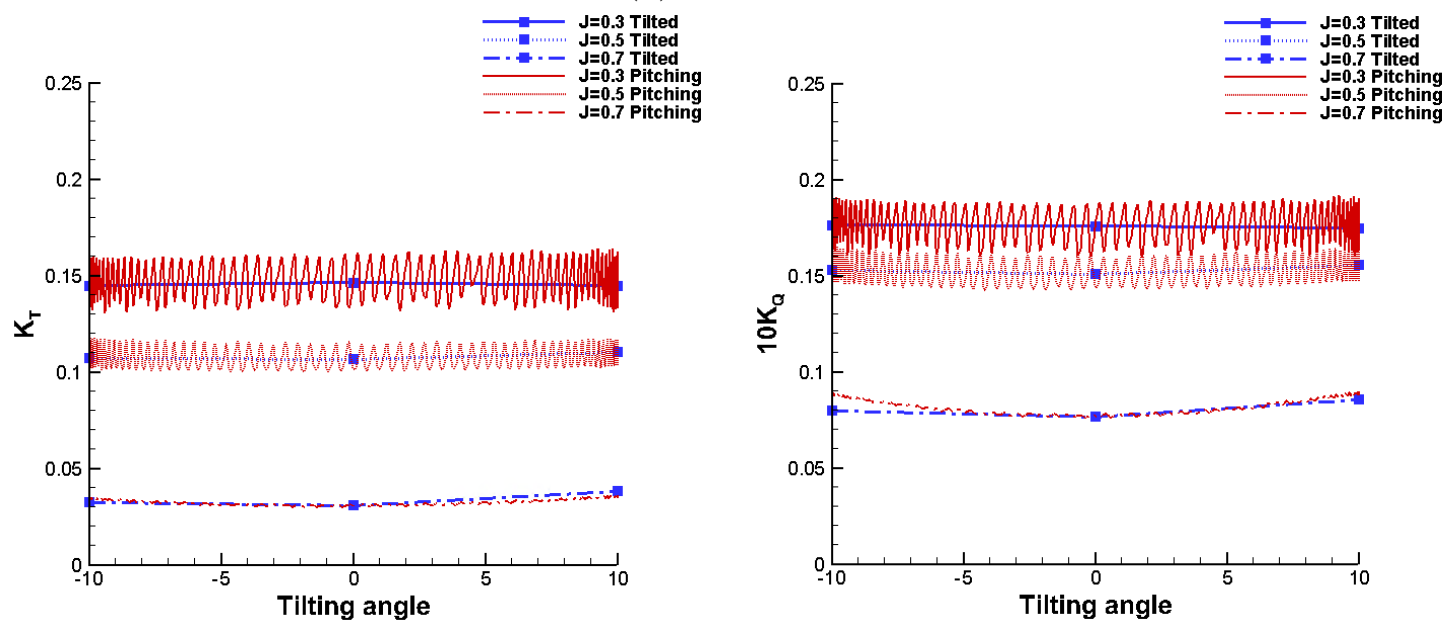

(c) $\mathrm{h} / \mathrm{D}=0.5$

Fig. 14 Comparison of the thrust and torque coefficients obtained with and without pitch motion

In the case of $\mathrm{h} / \mathrm{D}=2.0$ and $\mathrm{h} / \mathrm{D}=1.0$, all the values of the pitching propeller show good agreement with those obtained for the tilted propeller within error rate considered as numerical error. At $\mathrm{h} / \mathrm{D}=0.5$, the thrust and torque coefficients of pitching propeller show severe fluctuation in lower advance coefficient. It is because interaction between propeller and freesurface is become strengthened and the case of with pitch motion shows continuous change 
according to time variation. However, the mean value of with motion is almost same as without pitch motion.

As a result, the immersion depth is the most dominant factor in thrust and torque coefficients. In the case of the tilted propeller, changes in the immersion depth result in $1 \%$ changes in the thrust and torque. This numerical value is not a significant enough to change the POW curve. However, it should be considered to estimate the correct value for the POW performance in wave conditions.

\section{Conclusions}

The purpose of this study was to examine a method for the estimation of propulsion performance in waves. The performance of a propeller moving periodically with the movement of the ship was estimated, by comparing and analyzing the POW characteristics through numerical analysis of a propeller that forms a tilt angle under a free surface. All numerical analyses were carried out with a KP458 propeller and compared with POW characteristics from the NMRI. The Reynolds number used in the calculations was around $2.07 \times 10^{5}$ in $J_{A}=0.5$ to have the same conditions as the NMRI data.

The POW performance was compared with the performance of a tilted propeller in deep immersion depth $(\mathrm{h} / \mathrm{D}=2.0)$, and then the effect of the immersion depth $(\mathrm{h} / \mathrm{D}=2.0,1.0,0.5)$ was examined in the tilted state. Finally, sinusoidal pitch motion was applied to the propeller, and the results were compared with the data of the tilted propeller.

In the case of the tilted propeller, the numerical analysis did not produce a significant change in the thrust and torque coefficients when the angles at greater depths were varied from $-10^{\circ}$ to $10^{\circ}$ at $10^{\circ}$ intervals. However angular variations of thrust and torque fluctuate severely when the propeller gets more tilt angle. It should be considered to prevent the erosion of shaft, noise and vibration.

In the case of the tilted propeller at different immersion depths, the tendency of the POW characteristics followed the measured POW tendency at various immersion depths. When the free surface and the propeller tip were in close contact $(\mathrm{h} / \mathrm{D}=0.5)$, the changes in the thrust and torque coefficients were slightly different compared with the measured data at $\mathrm{h} / \mathrm{D}=2.0$.

The sinusoidal pitching propeller showed good agreement with the tilted propeller results with $1 \%$ error. The effect of the sinusoidal pitch motion was insignificant. Future research will be done on superposed motion of the propeller, which is a combination of sinusoidal heaving motion and pitching motion. The results could help to consider the real motion of a ship in waves.

\section{ACKNOWLEDGEMENTS}

This work was supported by INHA UNIVERSITY Research Grant.

\section{REFERENCES}

[1] Paik, K.-J., "Numerical study on the hydrodynamic characteristics of a propeller operating beneath a free surface," International Journal of Naval Architecture and Ocean Engineering, 9, pp. 655-667, 2017. https://doi.org/10.1016/j.ijnaoe.2017.02.006

[2] Lee, S., and Paik, K.-J., "URANS SIMULATION OF A PARTIALLY SUBMERGED PROPELLER OPERATING UNDER THE BOLLARD CONDITION,” Brodogradnja, 69, pp. 107-121, 2018. https://doi.org/10.21278/brod69107

[3] Kempf, G., "The influence of viscosity on thrust and torque of a propeller working near the surface," Transactions of the Institution of Naval Architects, pp. 321-326, London, UK, 1934

[4] Shiba, H., "Air Drawing of Marine Propellers," Transportation Technical Research Institute, Report no.9, Japan, Aug 1953. 
[5] Koushan, K., "Dynamics of ventilated propeller blade loading on thrusters," Proceedings of World Maritime Technology Conference, London, UK, October 2006.

[6] Kozlowska, A. M., Steen, S., and Koushan, K., "Classification of Different Type of Propeller Ventilation and Ventilation Inception Mechanism," First International Symposium on Marine Propulsors, SMP'09, Trondheim, Norway, June 2009.

[7] Kozlowska, A. M., Savio, L., and Steen, S., "Predicting Thrust Loss of Ship Propellers Due to Ventilation and Out of Water Effect," Journal of Ship Research, 61(4), pp. 198-213, 2017. https://doi.org/10.5957/JOSR.170004

[8] Faltinsen, O., Minsaas, K. J., Liapias, N., Skjordal, S. O., "Prediction of resistance and propulsion of a ship in a seaway," Proceedings of 13th symposium on Naval Hydrodynamics, Tokyo, Japan, 1980.

[9] Minsaas, K. J., Thon, H. J. and Kauczynski, W., "Estimation of Required Thruster Capacity for Operation of Offshore Vessels under Severe Weather Conditions," Proceedings of International Symposium on Practical Design of Ships and other Floating Structures, PRADS 1987, Trondheim, Nor-way, 1987.

[10] Koushan, K., Spence, S. J. B., Hamstad, T., "Experimental Investigation of the Effect of Waves and Ventilation on Thruster Loadings," First International Symposium on Marine Propulsors, SMP'09, Trondheim, Norway, June 2009.

[11] Koushan, K., "Dynamics of ventilated propeller blade loading on thrusters due to forced sinusoidal heave motion," Proceedings of 26th ONR Symposium on Naval Hydrodynamics, Rome, Italy, 2006.

[12] Koushan, K., "Dynamics of propeller blade and Duct Loading on Thrusters in Dynamic Positioning Mode," Dynamic Positioning Conference, Houston, Texas, USA, October 2007.

[13] Amini, H., Steen, S., "Experimental and Theoretical Analysis of Propeller Shaft Loads in Oblique Inflow," Journal of Ship Research, 55(4), pp. 1-21, 2011. https://doi.org/10.5957/JOSR.55.4.100044

[14] Li, Y., Martin, J. E., Michael, T., Carrica, P. M., "A Study of Propeller Operation Near a Free Surface," Journal of Ship Research, 59(4), pp. 190-200, 2015. https://doi.org/10.5957/JOSR.59.4.150042

[15] Shamsi, R., Ghassemi, H., "Numerical investigation of yaw angle effects on propulsive characteristics of podded propulsors," International Journal of Naval Architecture and Ocean Engineering, 5, pp. 287-301, 2013. https://doi.org/10.2478/IJNAOE-2013-0133

[16] Park, D-M., Seo, M-G., Lee, J-H., Yang, K-K., Kim, Y-H., "Systematic Experimental and Numerical Analyses on Added Resistance in waves," Journal of the Society of Naval Architects of Korea, 6, pp. 459479, 2014. https://doi.org/10.3744/SNAK.2014.51.6.459

[17] Kim, Y-C., Kim, K-S., Kim, J., Kim, Y-S., Park, I-R., Jang, Y-H., "Analysis of added resistance and seakeeping responses in head sea conditions for low-speed full ships using URANS approach," International Journal of Naval Architecture and Ocean Engineering, 9, pp. 1-14, 2014.

\footnotetext{
Submitted: $\quad$ 19.01.2019. $\quad$ Yoon-Ho Jang

Department of Naval Architecture and Ocean Engineering,

Accepted: $\quad$ 01.04.2020. Inha University, Incheon 22212, Republic of Korea

Meong-Jin Eom

Department of Naval Architecture and Ocean Engineering, Inha University, Incheon 22212, Republic of Korea

Kwang-Jun Paik (Corresponding author, kwangjun.paik@inha.ac.kr)

Department of Naval Architecture and Ocean Engineering,

Inha University, Incheon 22212, Republic of Korea

Sang-Hyun Kim

Department of Naval Architecture and Ocean Engineering, Inha University, Incheon 22212, Republic of Korea

Gisu Song

Samsung Ship Model Basin, Samsung Heavy Industries, Co., Ltd.,

Daejeon 34051, Republic of Korea
} 